\title{
Canalization effect in the coagulation cascade and the interindividual variability of oral anticoagulant response. a simulation Study
}

Alexandru D Corlan ${ }^{1,2}$ and John Ross ${ }^{3^{*}}$

\author{
* Correspondence: john. \\ ross@stanford.edu \\ ${ }^{3}$ Chemistry Department, Stanford \\ University, CA, USA \\ Full list of author information is \\ available at the end of the article
}

\begin{abstract}
Background: Increasing the predictability and reducing the rate of side effects of oral anticoagulant treatment (OAT) requires further clarification of the cause of about $50 \%$ of the interindividual variability of OAT response that is currently unaccounted for. We explore numerically the hypothesis that the effect of the interindividual expression variability of coagulation proteins, which does not usually result in a variability of the coagulation times in untreated subjects, is unmasked by OAT.

Results: We developed a stochastic variant of the Hockin-Mann model of the tissue factor coagulation pathway, using literature data for the variability of coagulation protein levels in the blood of normal subjects. We simulated in vitro coagulation and estimated the Prothrombin Time and the INR across a model population. In a model of untreated subjects a "canalization effect" can be observed in that a coefficient of variation of up to $33 \%$ of each protein level results in a simulated INR of 1 with a clinically irrelevant dispersion of 0.12 . When the mean and the standard deviation of vitamin-K dependent protein levels were reduced by $80 \%$, corresponding to the usual Warfarin treatment intensity, the simulated INR was $2.98 \pm 0.48$, a clinically relevant dispersion, corresponding to a reduction of the canalization effect.

Then we combined the Hockin-Mann stochastic model with our previously published model of population response to Warfarin, that takes into account the genetical and the phenotypical variability of Warfarin pharmacokinetics and pharmacodynamics. We used the combined model to evaluate the coagulation protein variability effect on the variability of the Warfarin dose required to reach an INR target of 2.5. The dose variance when removing the coagulation protein variability was 30\% lower. The dose was mostly related to the pretreatment levels of factors $\mathrm{VII}, \mathrm{X}$, and the tissue factor pathway inhibitor (TFPI).
\end{abstract}

Conclusions: It may be worth exploring in experimental studies whether the pretreatment levels of coagulation proteins, in particular VII, X and TFPI, are predictors of the individual warfarin dose, even though, maybe due to a canalizationtype effect, their effect on the INR variance in untreated subjects appears low.

Keywords: Interindividual variability, stochastic model, oral anticoagulant treatment, INR, coagulation cascade, canalization
C Biomed Central

(C) 2011 Corlan and Ross; licensee BioMed Central Ltd. This is an Open Access article distributed under the terms of the Creative Commons Attribution License (http://creativecommons.org/licenses/by/2.0), which permits unrestricted use, distribution, and reproduction in any medium, provided the original work is properly cited. 


\section{Background}

There is a continuing need to identify measurable causes of the substantial variability of the individual response to oral anticoagulants, such as warfarin or acenocoumarol. Finding such causes is required to improve predictability and consequently reduce the high levels of morbidity and mortality associated to these treatments. Together with anthropometric parameters, the known polymorphisms of CYP2C9 and VKORC1 enzymes currently account only for about $50 \%$ of the dose variability [1-3].

The relation between measurable sources of variability and the variability of the patient response to treatment is explained by the complex but extensively explored warfarin pharmacokinetics/pharmacodynamics (PK/PD).

In short, Warfarin is absorbed from the gut completely, then it blocks irreversibly the Vitamin-K epoxyde reductase complex 1 (VKORC1), an enzyme found mostly in the liver. It is eliminated by other liver enzymes, from the cytochrome P-450 family, mostly by CYP450-2C9. The blocking of the VKORC1 results in a depletion of reduced Vitamin-K that is oxidised by the $\gamma$-glutamyl-carboxylase enzyme (GGCX) symultaneously with the $\gamma$-carboxylation of the glutamate residues of protein precursors of coagulation factors II,VII,IX and X. The $\gamma$-carboxylation is necessary for their biological activity.

The variability of this $\mathrm{PK} / \mathrm{PD}$ process can be due to: genetic mutations of CYP2C9, VKORC1 and GGCX; mutations in the introns, exons or flanking sequences of these enzymes resulting in different phenotypical expression; variability in intake, transport and metabolism of vitamin-K; the size of the various organism compartments and in particular of the liver; the general synthesis capacity of the liver; simultaneous administration of drugs and foods that interact with various stages of the process, for example by inducing or repressing the expression of CYP450 enzymes.

The synthesis rate of coagulation factors, and their biological activity is also variable due to a number of mutations affecting both the structure and the expression rate of the precursors. The elimination rate is probably influenced by the general activation rate of the coagulation cascade in the bloodstream that also presents interindividual variability.

One potential cause of the response variability that has not been generally considered is that due to the genetic polymorphism and phenotypical expression of the proteins that intervene in the coagulation cascade. Their effect on the coagulation time, for example on the prothrombin time and its standardised equivalent-the International Normalised Ratio (INR), is low in the healthy population. Here we argue, based on a stochastic version of a well studied model of the extrinsic pathway of the coagulation cascade [4], that this effect should be low only in untreated subjects.

The canalization effect, $[5,6]$ is the relative robustness of key physiologic parameters, features and processes despite wide genetic and phenotypical variability of other factors, such as expression levels of proteins.

We believe this could be the case with the coagulation cascade: while there is substantial interindividual variability in the biological level of coagulation proteins, the cascade is organised such that the key blood coagulation time parameter is maintained within very narrow limits across the healthy population.

This would also explain why a very substantial reduction of the level of vitamin-K dependent factors (II,VII,IX,X) needs to be obtained in order to observe a clinically relevant prolongation of the prothrombin time. 
However, our simulations show that once this reduction is achieved, the canalization phenomenon is also supressed and the interindividual variability of the expression of coagulation proteins in treated subjects becomes manifest and needs to be corrected by adjusting the Warfarin dose.

\section{Methods}

The Hocking Mann model [4] is a system of ordinary differential equations that describe the kinetics of the sythesis of active thrombin once tissue factor is added to a sample of blood. It corresponds to the process that takes place in a test tube when the prothrombin time is measured.

We developed a stochastic version of the Hockin-Mann model of the tissue factor (extrinsic) pathway kinetics by replacing, in the equations from [4] the coefficients corresponding to the initial levels of factors II, V, VII, VIIa, VIII, IX, X, XI, antithrombinIII and tissue factor pathway inhibitor (TFPI) with normally distributed, independent, random variables. The coefficient of variation for each variable was estimated based on direct experimental determinations available in the literature (see Table 1).

We used a $5 \mathrm{nM}$ concentration for the initial level of the tissue factor, consistent with the conditions used when measuring the prothrombin time. We computed a simulated prothrombin time as the reaction time needed for activated factor II to reach a concentration of $20 \mathrm{nM}$.

From the results we computed the equivalent of the prothrombin time for each realisation and the mean normal prothrombin time (MNPT), as in [7], by averaging the normal prothrombin times. The INR (International Normalised Ratio) of a blood sample is the ratio of the prothrombin time for that sample to the MNPT.

As previously described in reference [8] this approach, using the Hockin-Mann model, leads to simulated results that are consistent with the experimentally observed

Table 1 Literature data on the dispersion of the coagulation protein levels

\begin{tabular}{|c|c|c|c|c|c|}
\hline protein & mean & sd & unit & $\begin{array}{l}\text { c.v. } \\
(\%)\end{array}$ & reference \\
\hline II (prothrombin) & 99.6 & 11.9 & $\%$ & 11.95 & Yamagishi 2010 [20] \\
\hline $\mathrm{V}$ (proaccelerin) & 105.4 & 33.6 & $\%$ & 31.88 & Yamagishi 2010 [20] \\
\hline \multirow[t]{5}{*}{ VII (proconvertin) } & 112.0 & 30.0 & $\%$ & 26.78 & Folsom 1997 [21] \\
\hline & 130.0 & 33.0 & $\%$ & 25.38 & Cushman 1996 [13] \\
\hline & 98.0 & 20.7 & $\%$ & 21.12 & Feng $2000[12]^{1}$, non-cvd \\
\hline & 99.5 & 26.2 & $\%$ & 26.33 & Feng $2000[12]^{1}$, non-thrombotic cvd \\
\hline & 93.6 & 31.7 & $\%$ & 33.87 & Feng $2000[12]^{1}$, thrombotic cvd \\
\hline \multirow[t]{2}{*}{$\overline{\mathrm{VIII}}$} & 120.0 & 37.0 & $\%$ & 30.83 & Cushman 1996 [13] \\
\hline & 127.0 & 40.0 & $\%$ & 31.50 & Folsom 1997 [21] \\
\hline IX & 88.5 & 29.3 & $\%$ & 33.11 & Yamagishi 2010 [20] \\
\hline $\bar{X}$ (prothrombinase) & 102.9 & 25.8 & $\%$ & 25.07 & Yamagishi 2010 [20] \\
\hline$\overline{X I}$ & 84.1 & 19.7 & $\%$ & 23.42 & Yamagishi 2010 [20] \\
\hline Antithrombin-III & 109.0 & 20.0 & $\%$ & 18.35 & Folsom 1997 [21] \\
\hline$\overline{T F P I}$ & 36.4 & 12.8 & $\mathrm{ng} / \mathrm{ml}$ & 35.16 & Zakai 2010 [22] \\
\hline
\end{tabular}

Literature experimental data on the dispersion of coagulation protein biological levels in the general population, as used in our simulations. In each case we computed C.V., the coefficient of variation, that is the ratio of the reported sd (standard deviation) to the reported mean. The unit used in most reports is a percentage from a standard laboratory value that is taken as $100 \%$ and is assumed close to the population average.

Values marked with "1" were estimated from the standard error of the mean and the number of cases from each groups of cvd (cardiovascular disease) patients. 
relation between the INR and the vitamin $\mathrm{K}$ dependent coagulation factor levels as reported in reference [9].

We simulated this model with a Monte Carlo implementation, by sampling the space of the variables and computing the kinetics of each of the species as proposed by Gillespie [10]. Each realisation corresponds to a simulated individual, and the whole dataset represents a simulation of the sample of the normal population.

The presence of stable anticoagulant treatment was simulated by uniformly reducing the initial levels of factors II, VII (and VIIa), IX and X down to 20\%. The proportional reduction was applied to each case in the randomly generated set, thus resulting in the reduction of both the mean and the standard deviation of the initial values of each variable.

We then combined the stochastic Hockin-Mann model with our 2008 stochastic model of warfarin pharmacodynamics [11], which is a detailed simulation of the kinetics of warfarin absorption, elimination, binding to VKORC1; vitamin $\mathrm{K}$ cycle; coagulation factor synthesis, $\gamma$-carboxylation, release and elimination. It is a set of ordinary differential equations with stochastic coefficients that represent interindividual variabilities.

This model was tuned with data in a population of mostly Caucasian adults and is able to reproduce the dynamics of INR response and dose variability as found in the literature.

In the combined system we computed the INR using a Hocking-Mann simulation instead of the formula from [9]. Thus, for each individual case, new initial parameters were added, consisting of the initial levels of the species involved in the HM model. The levels of coagulation proteins were generated as independent Gaussian variables with a coefficient of variation as specified in table 1 (the median value was taken when multiple literature determinations were available). Two series of Monte Carlo simulations were run: (A) in which an average value of the baseline coagulation factor levels was taken to be the same for all cases in the random set of parameters, but other individual parameters (VKORC1, CYP2C9, antropometric differences) were kept variable; (B) in which the variabilities present in table 1 were also included in the baseline parameter generation.

\section{Results and Discussion}

\section{Baseline factor levels vs INR}

As previously detailed in the methods section, we first simulated the coagulation of normal blood samples using a stochastic version of the Hockin-Mann extrinsic coagulation pathway model.

Figure 1 shows the distribution of the simulated INR values at various levels of the vitamin $\mathrm{K}$ dependent factors (II, VII, IX and X), following different treatment intensities. The baseline level (100\%) simulated sample resulted in a standard deviation of the INR of 0.12 .

For the highest treatment intensity, corresponding to an average INR of about 3, despite reducing the levels-and implicitly the dispersion-of the vitamin $\mathrm{K}$ dependent factors to $20 \%$ the standard deviation of the INR increased to 0.48 .

This result suggests that measuring the baseline levels of coagulation factors before treatment initiation might help with predicting the patient's sensitivity. As such 


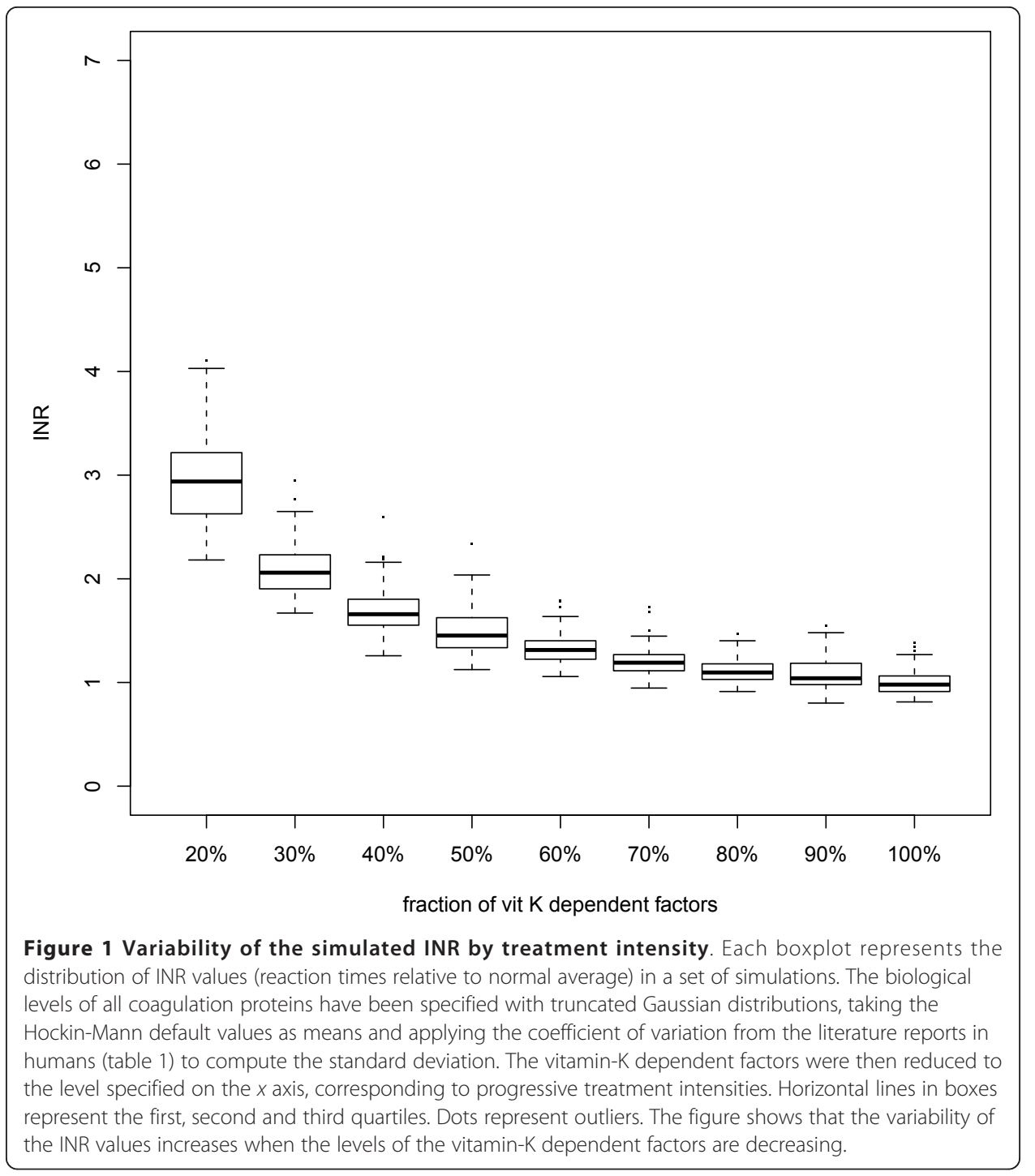

measurements would be quite expensive, it is important to see which factor levels have the strongest association with the INR.

Figures 2 and 3 show the relationship between the simulated level of each coagulation protein and the level of the INR in the healthy and treated scenarios, respectively.

Proconvertin and proaccelerin (factor VII and V) were important determinants of the INR value in untreated models. In the treated models factor $\mathrm{V}$ levels were not correlated with the INR value anymore, but factors VII, $\mathrm{X}$ and the TFPI were.

\section{Baseline factor levels and the warfarin dose}

We combined our previously developed model of the population response to warfarin [11] with the Hockin-Mann model for computing the instantaneous INR values.

We ran two series of Monte Carlo simulations: one (series A) in which the normal variability of both the pharmacokinetic/pharmacodynamic (PK/PD) and the factor variability were represented and a second (series B) in which the PK/PD variability was represented but all baseline levels of the coagulation proteins were the same in all cases. 

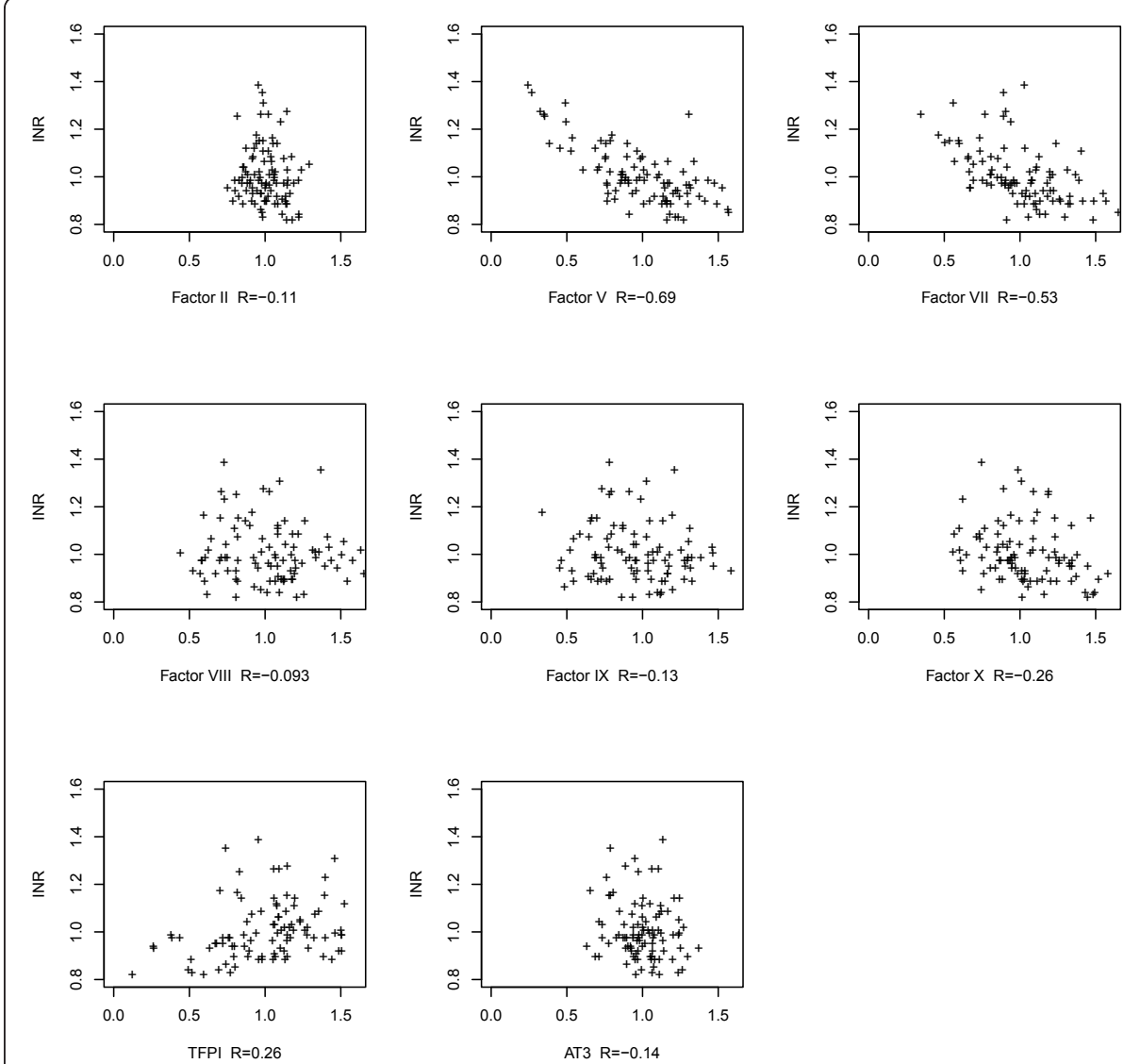

Figure 2 Individual factor levels vs the INR in scenarios representing untreated subjects. Vitamin-K dependent factors are at the baseline (pretreatment) level. $\mathrm{R}$ is the Pearson correlation coefficient for each plot. Each cross represents one point in the parameter space. The plot shows that factors $V$ and VII have the strongest correlations with the baseline INR.

For each case in each Monte Carlo series we searched for the optimal daily dose of Warfarin for a target INR.

For a therapeutic INR target of 2.5 , the dose in the population was $4.03 \pm 1.67 \mathrm{mg} /$ day in series B and $3.88 \pm 2.00 \mathrm{mg} /$ day in series A. Variances were 2.79 and 4.00 ; thus elimination of baseline variability of coagulation proteins led to a reduction of the simulated dose variance by $30 \%$.

Table 2 shows the correlation coefficients between the baseline levels of the coagulation proteins proteins and the dose. Correlations with the dose were also stronger for factors VII, $\mathrm{X}$ and the TFPI.

\section{Discussion}

Biological activity levels of plasma proteins involved in coagulation have been documented to exhibit a wide variability in normal subjects (see references from table 1). The fact this variability does not translate into an easily measurable variability of coagulation test results, such as the INR, that are based on measuring coagulation times in standardised conditions, is known in biology as "canalization" [5].

As a physiologic parameter, the optimal blood coagulation time is determined by the balance of the need to keep the blood flowing through all the blood vessels as long as 


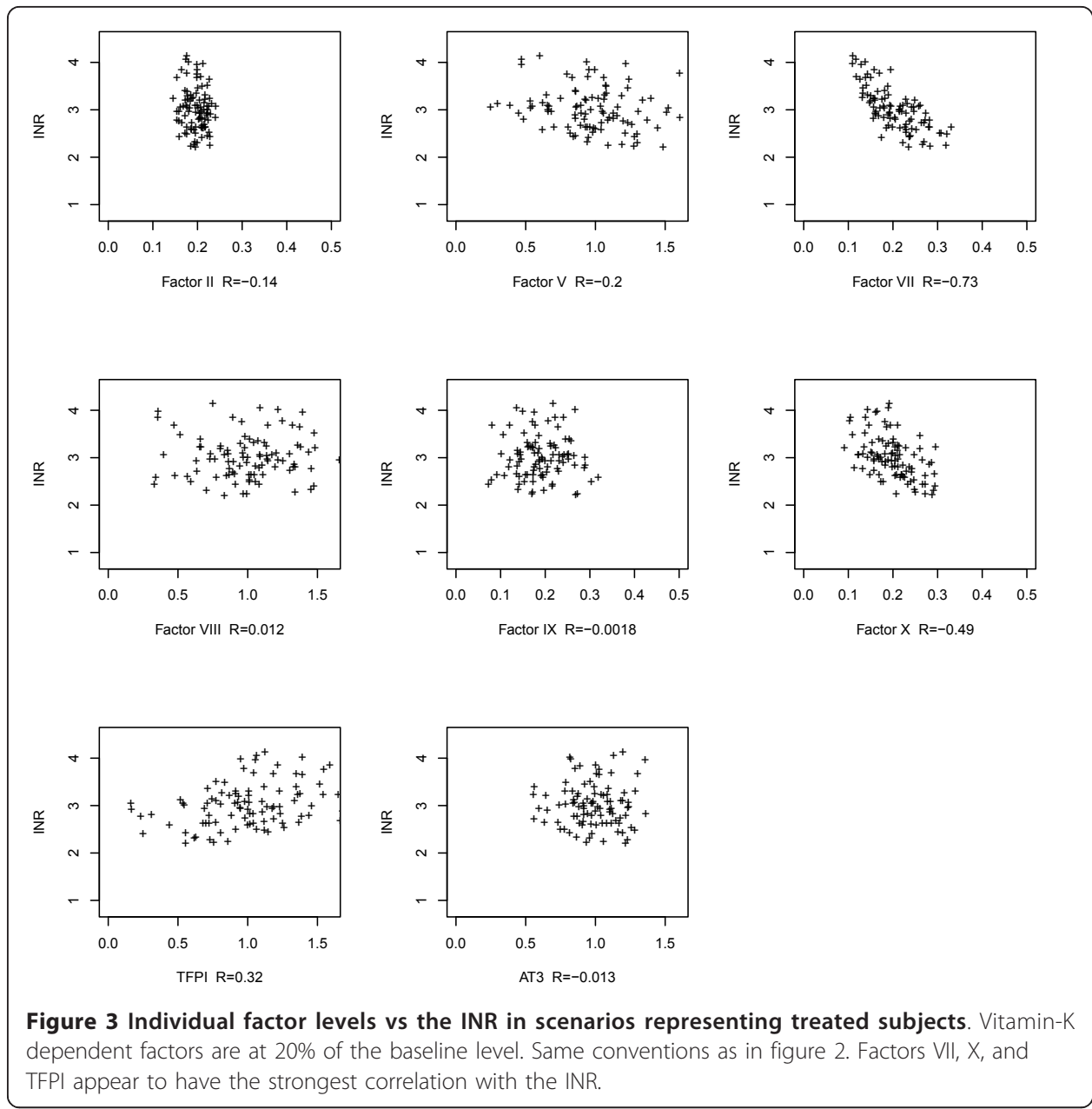

the organism is intact and the need for it to clot following any wounding. Over the time of the evolution, the elimination of organisms that do not meet these two simultaneous and opposite constraints may have amounted to a "stabilizing selection" process that resulted in the canalization effect.

Despite its low effect on the INR, the normal variability of the baseline levels of some of these proteins (II, VII, TFPI, VIII, von Willebrand factor) has been associated with the risk of cardiovascular events such as myocardial infarction and stroke [12,13]. This illustrates how a "canalized" effect, such as the normally low variability of the

Table 2 Correlation coefficients (R) of optimal warfarin dose vs. baseline coagulation protein levels

\begin{tabular}{lr}
\hline protein & $\mathbf{R}$ \\
\hline Factor II & 0.09 \\
Factor V & 0.07 \\
Factor VII & 0.32 \\
Factor X & 0.24 \\
Factor VIII & 0.09 \\
TFPI & -0.30 \\
AT-III & -0.01 \\
\hline
\end{tabular}

The strongest correlations were found for factors $\mathrm{VII}, \mathrm{X}$ and the tissue factor pathway inhibitor (TFPI). 
coagulation time, can hide variabilities in other dimensions that are relevant for pathological variability.

Our results suggest a similar effect may occur with the response to anticoagulant treatment: while pretreatment coagulation times exhibit a low variability, the underlying variability of the coagulation protein levels may be related to clinically relevant differences in treatment response.

In this simulation study we explored the relationship between the variability of the pretreatment plasmatic factor levels and the variability of the coagulation time. We showed that the canalization effect should also be reduced when oral anticoagulation of the same intensity is applied to all the simulated patients, unmasking the effect of interindividual pretreatment factor variability on the INR only for patients under treatment. We also show that, when warfarin doses are adjusted such that the same INR target is achieved, the interindividual variability of pretreatment coagulation protein levels in the blood should result in an interindividual variability of the necessary dose.

These factors are influenced by a variety of known genetic polymorphisms [14-16] but the influence of each polymorphism is relatively small and also there are other, important, phenotypical and transient influences $[17,18]$. Thus, determination of their baseline biological levels rather than their genotype should be most effective as INR response predictors. Assays used for accurately measuring coagulation protein levels in the blood are currently quite expensive; however, if the possible association described here is confirmed experimentally more practical pretreatment investigations, such as coagulation tests complementary to INR determination, might be developed.

\section{Limitations}

A limitation of our study is that we only considered a kinetic model of the extrinsic pathway of the coagulation cascade. Although this model was extensively validated with in vitro experimental data over the years, the particular implications we anticipated in this study need direct experimental verification as well.

The predictive value of the baseline coagulation protein levels may be lower than we expect as in our model we considered their synthesis and elimination processes stable in time for a given individual. The intraindividual variability $[17,18]$ as well as inaccuracies of factor level measurement methods [19] may result in an actually lower predictive value.

\section{Conclusion}

Our simulations suggest that in theory, to the extent of the validity of the Hockin-Mann model and our warfarin population effect model, the pretreatment levels of the coagulation proteins, in particular of factors X, VII and the TFPI may contribute to the variability of the response to warfarin. If experimental verification confirms our numeric predictions, measurement of the baseline levels of these proteins may further improve warfarin dose prediction.

We suspect that this type of effect -an unmasking of interindividual variability when some canalization effect is overcome-might also affect other types of treatments and pathological conditions and explain other causes of unexpected variability of the individual response. 


\section{List of abbreviations}

TFPI: tissue factor pathway inhibitor; AT-III: antithrombin III; II-XII: coagulation factors II to XII; HM: Hockin-Mann model (as described in reference 4); PK/PD: pharmacokinetic/pharmacodynamic; VKORC1: Vitamin K epoxyde reductase complex subunit 1; CYP2C9: Cytochrome P450 2C9; GGCX: Vitamin K dependent Y-glutamyl carboxylase; OAT: oral anticoagulant treatment; sd: standard deviation; c.v.: coefficient of variation; cvd: cardiovascular disease.

\section{Acknowledgements and Funding}

The design of this study is in part based on earlier discussions with our late colleague and friend, dr. Marcel Vlad. Dr. Octavian Voiculescu pointed out that the feature we observed is well known and is named canalization. One anonymous referee made numerous insightful observations that resulted in substantial clarifications of the text. Part of this work was supported by the National Science Foundation with the grant number: CHE 0847073. Computational resources were provided through the European Union POSCCE-A2-O2.2.3-2008 instrument. Funding bodies did not participate in any way in study design, the collection, analysis, and interpretation of data, the writing of the manuscript or the decision to submit the manuscript for publication.

\section{Author details}

${ }^{1}$ University Emergency Hospital, 169 Spl Independentei, Bucharest, Romania. ${ }^{2}$ Carol Davila' University of Medicine and Pharmacy, 21 Dionisie Lupu, Bucharest, Romania. ${ }^{3}$ Chemistry Department, Stanford University, CA, USA.

\section{Authors' contributions}

$A D C$ and JR designed the simulation experiments and wrote the paper. ADC performed the simulations and processed the results. All authors read and approved the final manuscript.

\section{Competing interests}

The authors declare that they have no competing interests.

Received: 21 March 2011 Accepted: 12 October 2011 Published: 12 October 2011

\section{References}

1. Linder MW, Homme MB, Reynolds KK, Gage BF, Eby C, Silvestrov N, Valdes R: Interactive Modeling for Ongoing Utility of Pharmacogenetic Diagnostic Testing: Application for Warfarin Therapy. Clinical Chemistry 2009 [http://www.ncbi. nlm.nih.gov/pubmed/19679631], [PMID: 19679631].

2. Li C, Schwarz UI, Ritchie MD, Roden DM, Stein CM, Kurnik D: Relative contribution of CYP2C9 and VKORC1 genotypes and early INR response to the prediction of warfarin sensitivity during initiation of therapy. Blood 2009, 113(17):3925-3930 [http://www.ncbi.nlm.nih.gov/pubmed/19074728], [PMID: 19074728].

3. Miao L, Yang J, Huang C, Shen Z: Contribution of age, body weight, and CYP2C9 and VKORC1 genotype to the anticoagulant response to warfarin: proposal for a new dosing regimen in Chinese patients. European Journal of Clinical Pharmacology 2007, 63(12):1135-1141 [http://www.ncbi.nlm.nih.gov/pubmed/17899045], [PMID: 17899045].

4. Hockin MF, Jones KC, Everse SJ, Mann KG: A Model for the Stoichiometric Regulation of Blood Coagulation. J Biol Chem 2002, 277(21):18322-18333 [http://www.jbc.org/cgi/content/abstract/277/21/18322].

5. Waddington C: Canalization of development and the inheritance of acquired characters. Nature 1942, 150:563-565 [http://www.nature.com/nature/journal/v150/n3811/abs/150563a0.html].

6. Siegal ML, Bergman A: Waddington's canalization revisited: Developmental stability and evolution. Proceedings of the National Academy of Sciences of the United States of America 2002, 99(16):10528-10532 [http://www.pnas.org/ content/99/16/10528.abstract].

7. Poller L, Ibrahim S, Keown M, Pattison A, Jespersen J: Simplified method for international normalized ratio (INR) derivation based on the prothrombin time/INR line: an international study. Clinical Chemistry 2010, 56(10):1608-1617 [http://www.ncbi.nlm.nih.gov/pubmed/20798354], [PMID: 20798354].

8. Vlad MO, Corlan AD, Morán F, Spang R, Oefner P, Ross J: Kinetic laws, phase-phase expansions, renormalization group, and INR calibration. Proceedings of the National Academy of Sciences 2009, 106(16):6465-6470[http://www.pnas. org/content/106/16/6465.abstract].

9. Watala C, Golanski J, Kardas P: Multivariate relationships between international normalized ratio and vitamin Kdependent coagulation-derived parameters in normal healthy donors and oral anticoagulant therapy patients. Thrombosis Journal 2003, 1:7 [http://www.ncbi.nlm.nih.gov/pubmed/14969588], [PMID: 14969588].

10. Gillespie DT: A general method for numerically simulating the stochastic time evolution of coupled chemical reactions. Journal of Computational Physics 1976, 22(4):403-434 [http://www.sciencedirect.com/science/article/B6WHY4DD1NC9-CP/2/43ade5f11fb949602b3a2abdbbb29f0e].

11. Vlad MO, Corlan AD, Morán F, Oefner P, Ross J: Incremental parameter evaluation from incomplete data with application to the population pharmacology of anticoagulants. Proceedings of the National Academy of Sciences of the United States of America 2008, 105(12):4627-32 [http://www.ncbi.nlm.nih.gov/pubmed/18353988], [PMID: 18353988].

12. Feng D, Toer GH, Larson MG, O'Donnell CJ, Lipinska I, Schmitz C, Sutherland PA, Johnstone MT, Muller JE, D'Agostino RB, Levy D, Lindpaintner K: Factor VII Gene Polymorphism, Factor VII Levels, and Prevalent Cardiovascular Disease: The Framingham Heart Study. Arterioscler Thromb Vasc Biol 2000, 20(2):593-600 [http://atvb. ahajournals.org/cgi/content/abstract/20/2/593].

13. Cushman M, Yanez D, Psaty BM, Fried LP, Heiss G, Lee M, Polak JF, Savage PJ, Tracy RP: Association of fibrinogen and coagulation factors VII and VIII with cardiovascular risk factors in the elderly: the Cardiovascular Health Study. Cardiovascular Health Study Investigators. American Journal of Epidemiology 1996, 143(7):665-676 [http://www.ncbi. nlm.nih.gov/pubmed/8651228], [PMID: 8651228].

14. Smith NL, Chen M, Dehghan A, Strachan DP, Basu S, Soranzo N, Hayward C, Rudan I, Sabater-Lleal M, Bis JC, de Maat M, Rumley A, Kong X, Yang Q, Williams FMK, Vitart V, Campbell H, Mälarstig A, Wiggins KL, Duijn CV, McArdle WL, Pankow JS, Johnson AD, Silveira A, McKnight B, Uitterlinden A, Aleksic N, Meigs JB, Peters A, Koenig W, Cushman M, 
Kathiresan S, Rotter Jl, Bovill EG, Hofman A, Boerwinkle E, Tofler GH, Peden JF, Psaty BM, Leebeek F, Folsom AR, Larson MG, Spector TD, Wright AF, Wilson JF, Hamsten A, Lumley T, Witteman JC, Tang W, O'Donnell CJ: Novel associations of multiple genetic loci with plasma levels of factor VII, factor VIII, and von Willebrand factor: The CHARGE Consortium. Circulation 2010, 121(12):1382-1392, [PMID: 20231535 PMCID: 2861278].

15. Athanasiadis G, Esteban E, -Vidal MGA, Dugoujon J, Moschonas N, Chaabani H, Bissar-Tadmouri N, Harich N, Stoneking M, Moral P: Different Evolutionary Histories of the Coagulation Factor VII Gene in Human Populations? Annals of Human Genetics 2010, 74:34-45 [http://onlinelibrary.wiley.com/doi/10.1111/j.1469-1809.2009.00557.x/abstract; jsessionid $=$ 4DCODB6F30E50B4075F933717FCDF73F.d03t01].

16. Nour M, Slama FB, Monastiri K, Hammami M, Helal AN: Prevalence in a Tunisian Arabic population of factor VII DNA variants and relation to factor VII plasma levels. Clinica Chimica Acta 2004, 349(1-2):199-202 [http://www. sciencedirect.com/science/article/B6T57-4D5KY6R-2/2/98e6f7a6c35c2f6eb54e86be779994de].

17. Pinotti M, Bertolucci C, Portaluppi F, Colognesi I, Frigato E, Foa A, Bernardi F: Daily and Circadian Rhythms of Tissue Factor Pathway Inhibitor and Factor VII Activity. Arterioscler Thromb Vasc Biol 2005, 25(3):646-649 [http://atvb. ahajournals.org/cgi/content/abstract/25/3/646].

18. Kapiotis S, Jilma B, Quehenberger P, Ruzicka K, Handler S, Speiser W: Morning Hypercoagulability and Hypofibrinolysis: Diurnal Variations in Circulating Activated Factor VII, Prothrombin Fragment F1+2, and Plasmin? Plasmin Inhibitor Complex. Circulation 1997, 96:19-21 [http://circ.ahajournals.org/cgi/content/abstract/96/1/19].

19. Green D, McMahon B, Foiles N, Tian L: Measurement of hemostatic factors in EDTA plasma. American Journal of Clinical Pathology 2008, 130(5):811-815 [http://www.ncbi.nlm.nih.gov/pubmed/18854275], [PMID: 18854275].

20. Yamagishi K, Aleksic N, Hannan PJ, Folsom AR: Coagulation Factors II, V, IX, X, XI, and XII, Plasminogen, and $a-2$ Antiplasmin and Risk of Coronary Heart Disease. Journal of Atherosclerosis and Thrombosis 2010, 17(4):402-409.

21. Folsom AR, Wu KK, Rosamond WD, Sharrett AR, Chambless LE: Prospective Study of Hemostatic Factors and Incidence of Coronary Heart Disease: The Atherosclerosis Risk in Communities (ARIC) Study. Circulation 1997, 96(4):1102-1108 [http://circ.ahajournals.org/cgi/content/abstract/96/4/1102]

22. Zakai NA, Lutsey PL, Folsom AR, Heckbert SR, Cushman M: Total Tissue Factor Pathway Inhibitor and Venous Thrombosis: The Longitudinal Investigation of Thromboembolism Etiology. Thrombosis and haemostasis 2010, 104(2):207-212, [PMID: 20431849 PMCID: 2943145].

doi:10.1186/1742-4682-8-37

Cite this article as: Corlan and Ross: Canalization effect in the coagulation cascade and the interindividual variability of oral anticoagulant response. a simulation Study. Theoretical Biology and Medical Modelling 2011 8:37.

\section{Submit your next manuscript to BioMed Central and take full advantage of:}

- Convenient online submission

- Thorough peer review

- No space constraints or color figure charges

- Immediate publication on acceptance

- Inclusion in PubMed, CAS, Scopus and Google Scholar

- Research which is freely available for redistribution 